OPEN ACCESS

Edited by:

Thomas E. Hanson,

University of Delaware, United States

Reviewed by:

Barny Whitman,

University of Georgia, United States Biswarup Mukhopadhyay,

Virginia Tech, United States

${ }^{*}$ Correspondence: Donald J. Ferguson Jr. fergusdj@miamioh.edu

Specialty section:

This article was submitted to Microbial Physiology and Metabolism,

a section of the journal

Frontiers in Microbiology

Received: 09 August 2019

Accepted: 23 October 2019

Published: 07 November 2019

Citation:

Creighbaum AJ, Ticak T,

Shinde $S$, Wang $X$ and Ferguson DJ Jr (2019) Examination of the Glycine Betaine-Dependent Methylotrophic Methanogenesis Pathway: Insights Into Anaerobic Quaternary Amine Methylotrophy. Front. Microbiol. 10:2572. doi: 10.3389/fmicb.2019.02572

\section{Examination of the Glycine Betaine-Dependent Methylotrophic Methanogenesis Pathway: Insights Into Anaerobic Quaternary Amine Methylotrophy}

\author{
Adam J. Creighbaum ${ }^{1}$, Tomislav Ticak ${ }^{2}$, Shrameeta Shinde ${ }^{1}$, Xin Wang ${ }^{1}$ and \\ Donald J. Ferguson Jr. 1,3*
}

1 Department of Microbiology, Miami University, Oxford, OH, United States, ${ }^{2}$ Department of Biological Sciences, University of Idaho, Moscow, ID, United States, ${ }^{3}$ Department of Biological Sciences, Miami University Regionals, Hamilton, OH, United States

Recent studies indicate that environmentally abundant quaternary amines (QAs) are a primary source for methanogenesis, yet the catabolic enzymes are unknown. We hypothesized that the methanogenic archaeon Methanolobus vulcani B1d metabolizes glycine betaine (GB) through a corrinoid-dependent GB:coenzyme M (CoM) methyl transfer pathway. The draft genome sequence of $M$. vulcani B1d revealed a gene encoding a predicted non-pyrrolysine MttB homolog (MV8460) with high sequence similarity to the GB methyltransferase encoded by Desulfitobacterium hafniense Y51. MV8460 catalyzes GB-dependent methylation of free cob(I)alamin indicating it is an authentic MtgB enzyme. Proteomic analysis revealed that MV8460 and a corrinoid binding protein (MV8465) were highly abundant when M. vulcani B1d was grown on GB relative to growth on trimethylamine. The abundance of a corrinoid reductive activation enzyme (MV10335) and a methylcorrinoid:CoM methyltransferase (MV10360) were significantly higher in GB-grown B1d lysates compared to other homologs. The GB:CoM pathway was fully reconstituted in vitro using recombinant MV8460, MV8465, MV10335, and MV10360. Demonstration of the complete GB:CoM pathway expands the knowledge of direct QA-dependent methylotrophy and establishes a model to identify additional ecologically relevant anaerobic quaternary amine pathways.

Keywords: methanogenesis, quaternary amine, one-carbon, COG5598, glycine betaine

\section{INTRODUCTION}

Methane is a greenhouse gas with approximately 28 times greater potency than carbon dioxide $\left(\mathrm{CO}_{2}\right)$ and is an important common fuel source (Auffret et al., 2017). To better understand the roles of methane in biogeochemical cycles and climate change, we must determine the routes of biological methane production and precursors for methanogenesis. The atmospheric concentration of methane is increasing (Yvon-Durocher et al., 2014) and this increase triggers feedback loops by releasing carbon from the permafrost in polar regions leading to increased methanogenesis (Olefeldt et al., 2013; Deng et al., 2017). Methanogenesis increases in response to elevated temperature, and methanogens demonstrate a larger temperature dependent 
flux than photosynthetic and other $\mathrm{CO}_{2}$ respiring organisms (Yvon-Durocher et al., 2014). Therefore, methane represents a larger percentage of increased atmospheric carbon emissions in response to warming (Yvon-Durocher et al., 2014). Our ability to predict future increases in methane relies upon expanding our knowledge of methanogenesis mechanisms, including those from higher order methylated ammonium compounds which are environmentally abundant (Mausz and Chen, 2019).

Methanogenesis proceeds through three known pathways: hydrogenotrophic, aceticlastic, and methylotrophic (Ferry, 2011). Methylotrophic methanogenesis has been well described from methanol, simple methylamines, and methylated sulfur compounds (Ferguson et al., 1996; Ferguson and Krzycki, 1997; Sauer et al., 1997; Sauer and Thauer, 1998, Ferguson et al., 2000; Tallant et al., 2000). In general, these pathways consist of a substrate-specific methyltransferase $(\mathrm{Mt} x \mathrm{~B})$, a cognate corrinoid binding protein $(\mathrm{Mt} x \mathrm{C})$, and a secondary methylcorrinoid:coenzyme $\mathrm{M}$ methyltransferase $(\mathrm{Mt} x \mathrm{~A})$. The $x$ represents a substrate-specific designation for each protein ( $\mathrm{a}=$ methanol, $\mathrm{t}=$ trimethylamine $(\mathrm{TMA}), \mathrm{b}=$ dimethylamine $(\mathrm{DMA}), \mathrm{m}=$ monomethylamine $(\mathrm{MMA})$, and $\mathrm{s}=$ methylated sulfurs), except in the case of MtbA which can function in each of the three simple methylamine pathways (Ferguson et al., 1996; Ferguson and Krzycki, 1997). Additionally, an ATP-dependent activation enzyme such as RamA is intermittently required for reductive activation of the corrinoid binding protein $\mathrm{Mt} x \mathrm{C}$ to the catalytically active Co(I) state (Ferguson et al., 2009). Once activated, the corrinoid binding protein can accept a methyl group from the substrate whose transfer is catalyzed by the Mt $x$ B. The methylated Mt $x \mathrm{C}$ then acts as a substrate for the $\mathrm{Mt} x \mathrm{~A}$ for transfer of the methyl group to coenzyme M (CoM). The methyl-CoM then acts as a substrate for methyl-CoM methylreductase for production of methane (Ferry, 2011). During methylotrophic methanogenesis, reducing equivalents for reducing the methyl group on methyl-CoM to methane are typically gained by oxidizing one out of every four methyl groups to $\mathrm{CO}_{2}$, however, some methanogens use molecular hydrogen $\left(\mathrm{H}_{2}\right)$ as an energy source to drive the pathway (Borrel et al., 2013; Enzmann et al., 2018).

A fortunate consequence of the study of methanogenesis from methylamines was the discovery of the genetically encoded amino acid L-pyrrolysine (Pyl) (Krzycki, 2005). It is suggested that Pyl evolved independently in each of the predicted active sites of $\mathrm{MttB}, \mathrm{MtbB}$, and $\mathrm{MtmB}$ as they are non-homologous enzymes, and removal of $\mathrm{Pyl}$ abolishes methanogenesis from each of the methylamine substrates (Krzycki, 2005). The TMA methyltransferase, MttB, is the namesake member of the widespread MttB COG5598 superfamily of enzymes, which has members spanning hundreds of species from both Bacteria and Archaea (Ticak et al., 2014). Interestingly, most members of COG5598 lack Pyl and are therefore likely not functional TMA methyltransferases. We recently showed that one non-Pyl (or Pyl-lacking) MttB homolog from Desulfitobacterium hafniense Y51 (DhMtgB) is a glycine betaine (GB) methyltransferase, suggesting a role of this family in breaking down higher order methylated ammonium compounds (Ticak et al., 2014).
Quaternary amines (QAs) are known to contribute to methanogenesis indirectly due to their breakdown by fermentative bacteria, which generates TMA (King, 1984). This is particularly important in marine environments where methylotrophic methanogens compete well, due to high sulfate concentrations in the sediments (Purdy et al., 2003). Recently, some methanogens have been reported to utilize QAs as a direct substrate (Tanaka, 1994; Watkins et al., 2012, 2014; Ticak et al., 2015). Several QAs, such as GB, choline, carnitine, and tetramethylammonium (QMA) are naturally produced and are utilized by organisms for functions as diverse as stabilizing osmotic pressure, biosynthesis, metabolizing fatty acids, or as toxic agents for defense (Rebouche and Seim, 1998; Craciun and Balskus, 2012; Ticak et al., 2014).

Despite all the work done on methylotrophic methanogenesis pathways, little is known about the pathways for QAdependent methanogenesis. Methanogenesis from QMA was shown to proceed via the methylotrophic pathway using proteins apparently unique to its pathway (Asakawa et al., 1998). Unfortunately, the QMA-utilizing Methanococcoides strain NaT1 was lost and no genomic information was reported, leaving many unanswered questions regarding QA-dependent methanogenesis. Particularly, the sequence identity of the QMA:corrinoid methyltransferase (MtqB) compared to other analogous methyltransferases is unknown and whether MtqB contained Pyl is also unknown.

The GB-utilizing methanogen Methanolobus vulcani B1d (B1d) isolated by our laboratory (Ticak et al., 2015) is the focus of this study to address questions pertaining to methanogenesis from QAs. Here we report the pathway by which B1d performs direct GB-dependent methanogenesis. Consistent with our original published hypotheses (Ticak et al., 2015), we determined that methanogenesis from GB is initiated by a COG5598 methyltransferase and proceeds through a corrinoiddependent pathway to methylate CoM. To our knowledge, this is the first reported intact methanogenic QA:CoM pathway that utilizes a Pyl-lacking MttB homolog and serves as a benchmark for further investigations into other QAs found naturally in the environment.

\section{RESULTS}

\section{Proteomic Analysis}

Significant gaps in knowledge remain regarding the pathways for methanogenesis from QAs. To begin addressing these gaps we analyzed the draft genome of B1d (Accession number VIAQ00000000) for genes of interest (Supplementary Table S1) and undertook a proteomic analysis of B1d during growth on GB, TMA, or methanol. GB-grown B1d compared to methanolor TMA-grown B1d showed significant increases in MV8460 (Figure 1 and Supplementary Figure S1), a putative Pyl-lacking homolog of MttB from the COG5598 superfamily. The adjacently encoded putative cognate corrinoid binding protein (Figure 2), MV8465, showed significant increases in protein levels when growing in GB compared to methanol or TMA. The putative GB transporter, MV8455, encoded adjacent to MV8460 was 

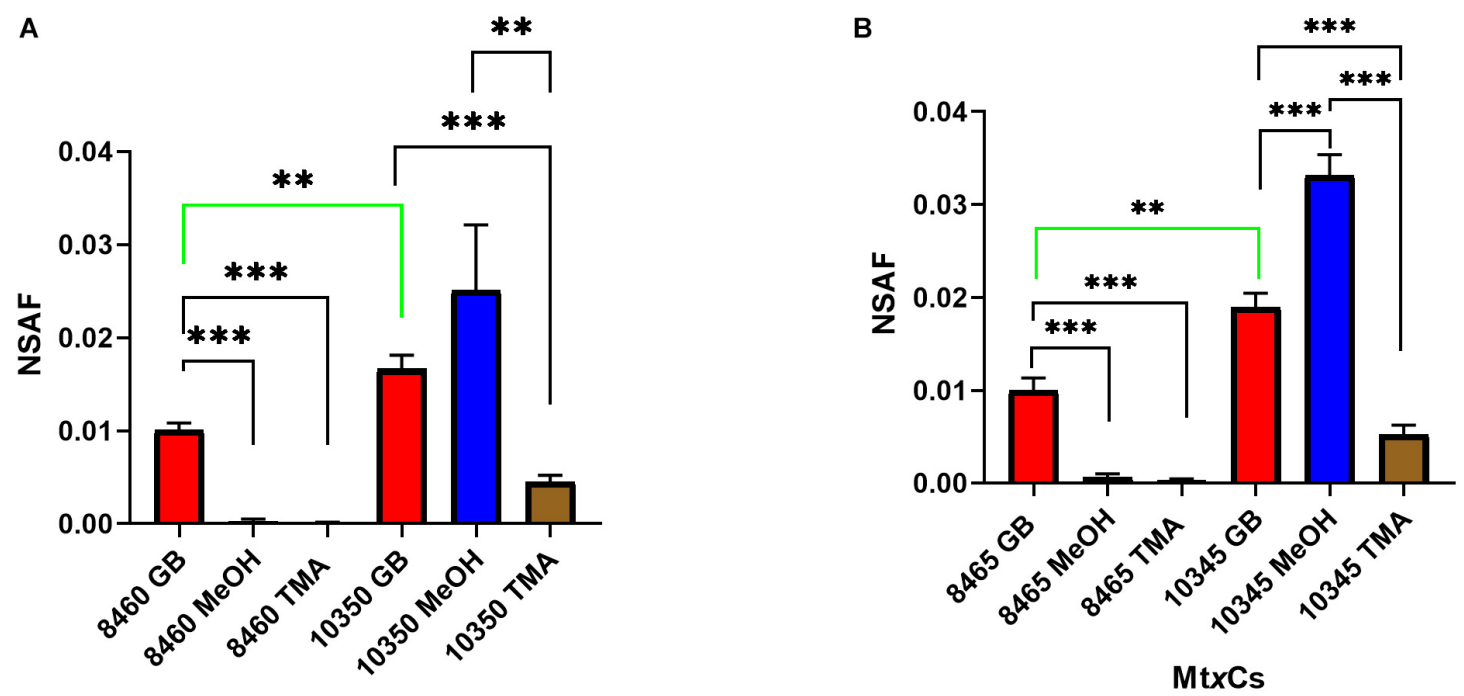

MtxBs

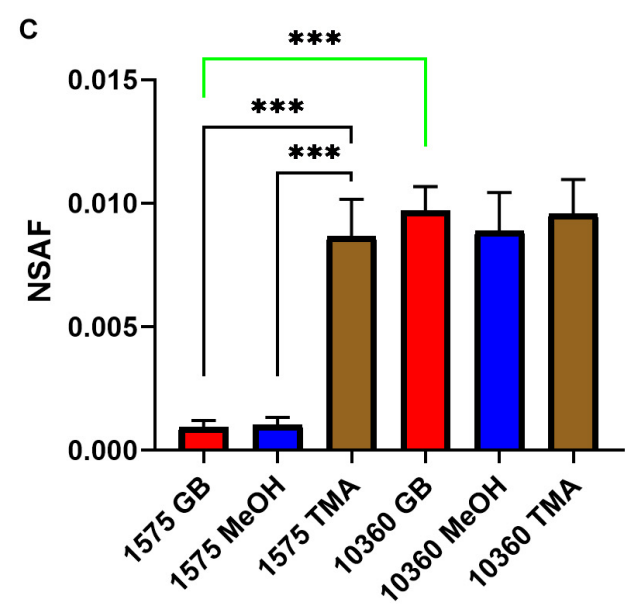

MtxAs

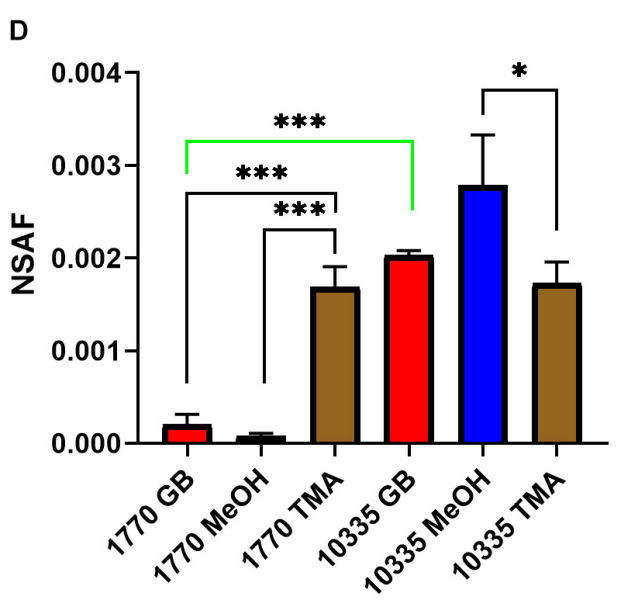

Ram

FIGURE 1 | Proteomic analysis of likely candidate proteins for GB-dependent CoM methylation were analyzed: MtxBs (A), MtxCs (B), MtxAs (C), and Ram (D) enzymes during B1d growth on GB, methanol, or TMA as the sole carbon source. Protein abundances were estimated by using the normalized spectral abundance factor (NSAF). Significant differences are indicated as follows when comparing individual protein levels between substrates: $p \leq 0.05$ are shown by $\left(^{*}\right), p \leq 0.01$ are shown by $(* *)$, and $p \leq 0.001$ are shown by $(* * *)$. The green bar indicates a significant difference between levels of analogous enzymes produced when grown on GB. Error bars represent standard deviations $(n=3)$.

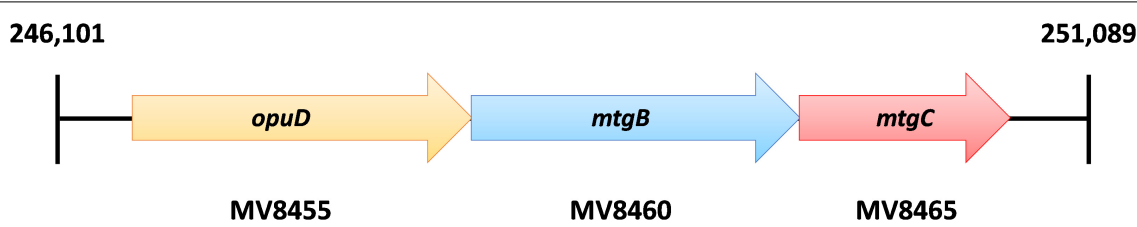

FIGURE 2 | The genome of B1d encodes for a single homologous MttB that lacks pyrrolysine, $m$ tgB (MV8460). Directly upstream of $m$ tgB is the predicted GB transporter, opuD, and downstream is the cognate corrinoid binding protein, $m$ tgC.

present only during growth on GB (Supplementary Figure S1). MV10335, a RamM homolog required for activation of corrinoid binding proteins, was produced in significantly higher amounts during growth on methanol compared to TMA but levels on GB were not significantly different to methanol or TMA. MV10360, a MtaA homolog required for methylation of CoM, was produced at equal levels during growth on each substrate. However, compared to their homologs (MV1575 and MV1770) MV10360 
and MV10335 were significantly higher during growth on GB. In addition to MV10335 and MV10360, MV10345 (MtaC) and MV10350 (MtaB) were present during growth on each substrate, suggesting the possibility of an available intact methanol:CoM pathway regardless of substrate.

\section{Phylogenetic Tree and Sequence Acquisition}

We generated an updated COG5598 phylogenetic tree (Figure 3), from our prior analysis (Ticak et al., 2014). The WAG + CAT (Whelan and Goldman, 2001) tree provided the fewest badsplits (17/2358) and the best log-likelihood (-1119437.408) with a $\Delta$ log-likelihood (7.948). The clade that contains the bonafide MtgB from D. hafniense Y51 (DhMtgB) was analyzed for organisms reported to grow anaerobically with GB. The majority of the reported organisms capable of anaerobic GB-dependent growth from the clade are Clostridiales, with only two archaeal members present: Methanococcoides vulcani SLH33(T) and B1d (Muller et al., 1981; Möller et al., 1984; Dehning et al., 1989; Finster et al., 1997; Kuhner et al., 1997; Nielsen et al., 2006; Sattley and Madigan, 2007; Sikorski et al., 2010; LHaridon et al., 2014; Ticak et al., 2014, 2015; Poehlein et al., 2015; Lechtenfeld et al., 2018).

\section{Structural Modeling of MV8460}

Based on the draft B1d genome, MV8460 is the sole Pyllacking MttB found in B1d, which is $65 \%$ identical and has $83 \%$ sequence similarity to DhMtgB. We therefore generated models of MV8460 using the apo-crystal structure of DhMtgB (PDB - 2QNE) as a template and compared the structures and predicted active sites of the two enzymes (Figure 4). The model of MV8460 generated using I-TASSER was the most accurate [C-score (2), TM-score (0.99 \pm 0.04), and RMSD $(2.9 \pm 2.1 \AA)]$ when compared to $2 \mathrm{QNE}$. The structural motifs of DhMtgB and MV8460 are $\alpha / \beta$ TIM-barrel folds, much like other methyltransferase enzymes (Hao et al., 2002; Hagemeier et al., 2006). MetaPocket 2.0 (Huang, 2009) highlighted an eight $\beta$-sheet orientation in the center of the enzyme which generates a deep funnel that was indicated as a possible region for GB interaction. GB was docked at this location in DhMtgB with a predicted $\mathrm{kCal} / \mathrm{mol}$ of -3.9 and MV8460 with a predicted $\mathrm{kCal} / \mathrm{mol}$ of -3.7 and their global structures overlaid (Figures 4A,B).

The binding sites of the overlapped structures were analyzed for conserved or semi-conserved residues reported to bind GB and an active site logo was generated (Figure 4C). Various crystal structures of GB-binding enzymes; 1R9L (Schiefner et al., 2004), 6EYG, 3TMG (Li et al., 2015), 1SW2 (Li et al., 2015), 2B4L (Horn et al., 2006), 4MJW (Salvi et al., 2014), and 3L6H (Wolters et al., 2010); not related to the COG5598 superfamily, were used to validate the modeled GB ligand. The predicted binding site of GB in DhMtgB and MV8460 is most comparable to the GB-bound 4MJW crystal. The S101, H466, and N510 residues in 4MJW coordinate the carboxyl moiety of GB for cation$\pi$ interactions with the surrounding aromatics. This suggests that four predicted active site residues may interact with GB

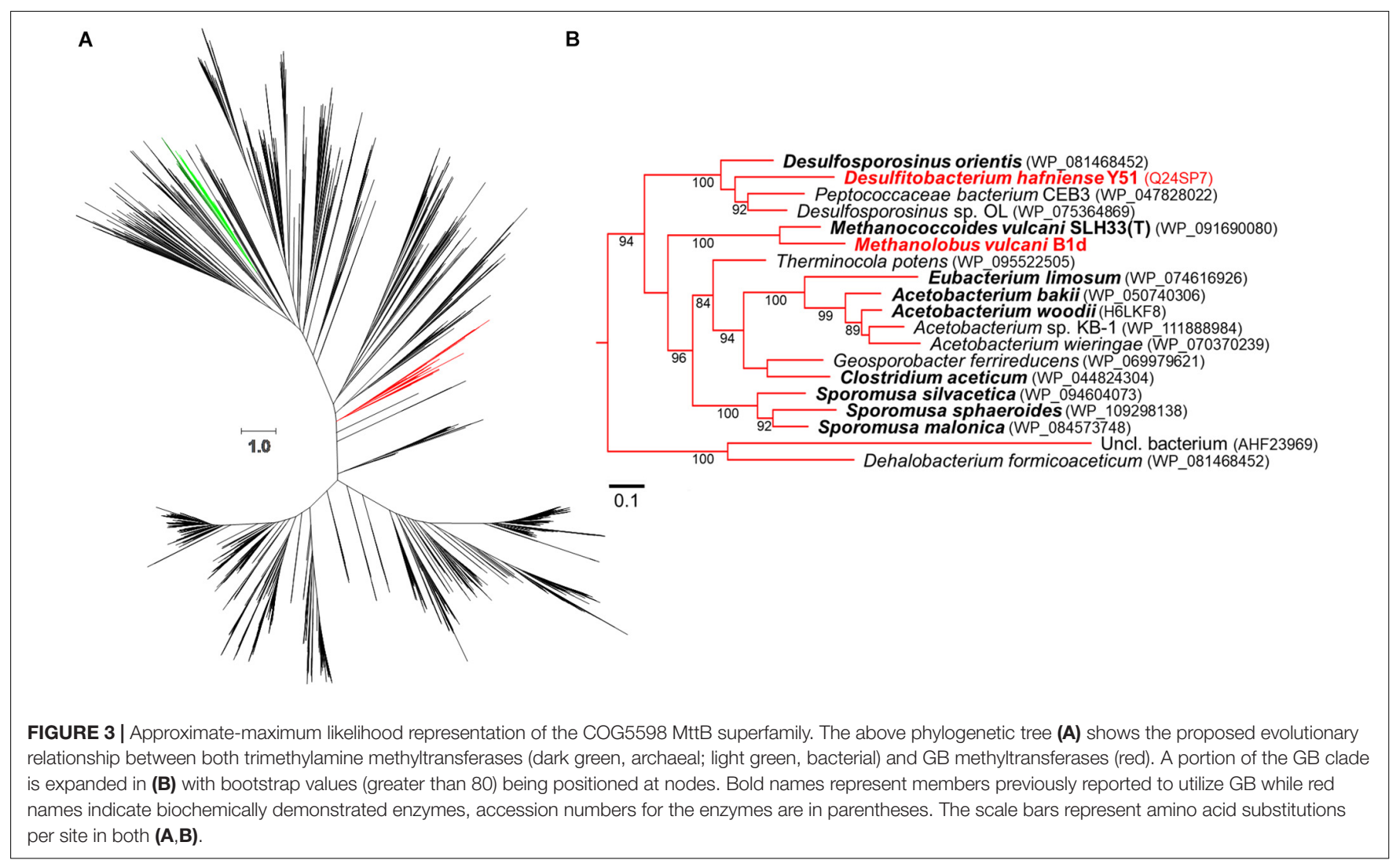



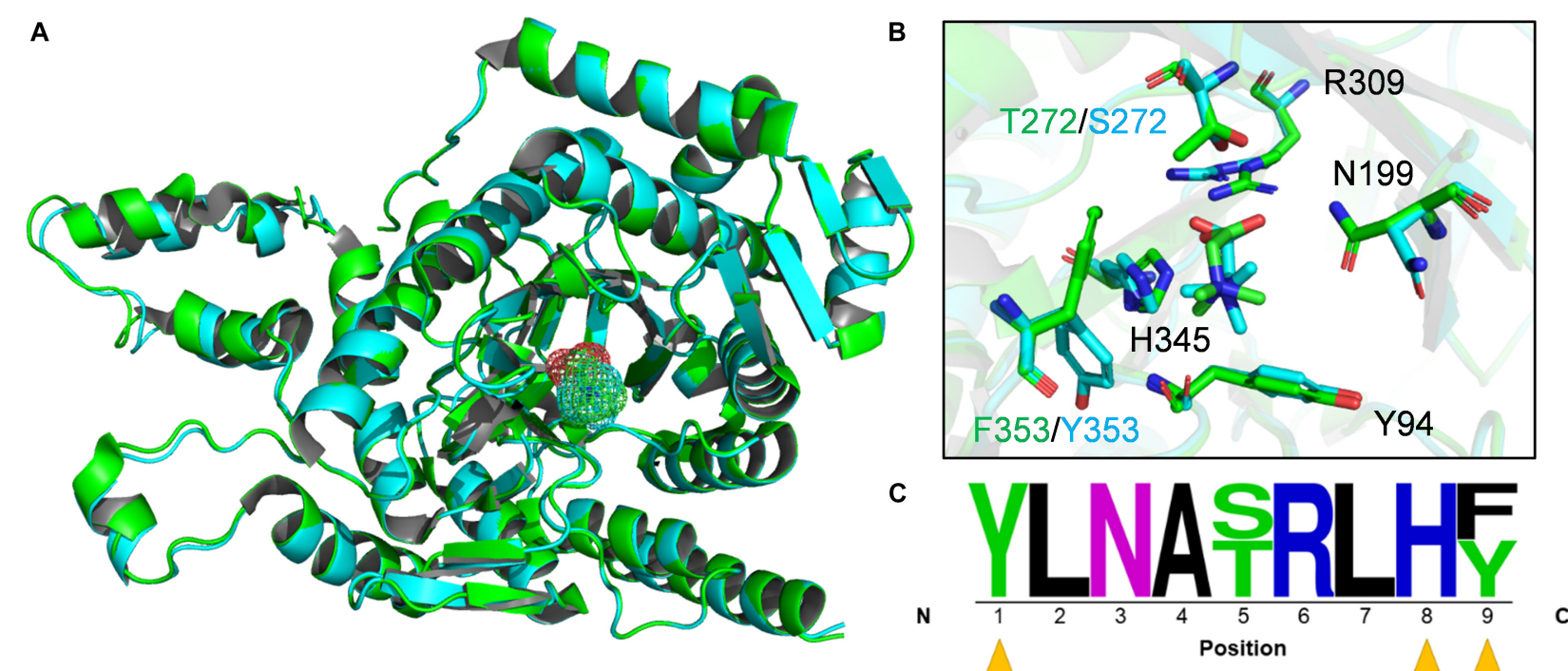

FIGURE 4 | Active site predictions of DhMtgB and MV8460. (A) The models represent the aligned global structure of DhMtgB (green) docked to GB (green mesh) and homology model of MV8460 (cyan) docked to GB (cyan mesh). (B) The proposed interacting residues of both DhMtgB and MV8460 are shown within the TIM-barrel funnel which was highlighted with MetaPocket 2.0 (Huang, 2009). Black labeled residues indicate those shared between both structures while divergent amino acids are coded by either green (DhMtgB) or cyan (MV8460). (C) Active site logo generated after aligning both DhMtgB and MV8460 residues within 4-5 ^̊ of the proposed docking site of GB were highlighted and aligned from $\mathrm{N}$-terminus to $\mathrm{C}$-terminus. Yellow arrows indicate aromatic residues which may interact in cation- $\pi$ interaction with the methyl moiety of GB.

as they are conserved between DhMtgB and MV8460: Y94, N199, R309, and H345.

\section{MV8460 GB:cob(l)alamin Activity}

We hypothesized that the MV8460 was responsible for initiating methanogenesis from GB by catalyzing the corrinoid-dependent demethylation of the substrate, analogous to the function of DhMtgB (Ticak et al., 2014). We detected methylation of free cob(I)alamin by MV8460 using GB as the methyl donor, exhibited by an increase at $540 \mathrm{~nm}$ (Figure 5A). Cob(I)alamin and methylcob(III)alamin share an isosbestic point at $578 \mathrm{~nm}$ which is disrupted in the presence of cob(II)alamin (Kreft and Schink, 1993; Ticak et al., 2014). Inadvertent oxidation of cob(I)alamin can cause a false positive due to the formation of cob(II)alamin, causing increases at 540 and $578 \mathrm{~nm}$ (Kreft and Schink, 1993; Ticak et al., 2014). Absorbance at $578 \mathrm{~nm}$ remained unchanged throughout the assay, suggesting a direct conversion of cob(l)alamin to methylcob(III)alamin (Figure 5B). The specific activity of the recombinant MV8460 under the conditions tested was $0.21 \mu \mathrm{mol} \mathrm{min}{ }^{-1} \mathrm{mg}^{-1}$. Activity was not detected when choline, TMA, or QMA were used as methyl donor substrates.

\section{MV8465 Reduction by MV10335 Followed by Methylation of MV8465 by MV8460}

In Methanosarcina barkeri, reduction of the corrinoid binding proteins in the TMA, DMA, and MMA pathways relies on the RamA enzyme, and likewise, reduction of the corrinoid binding proteins in the methanol pathway relies on RamM (Ferguson et al., 2009). MV8465 displayed the characteristic
UV-visible spectrum of a corrinoid binding protein (Figure 6A; Ferguson and Krzycki, 1997). We tested the ability of MV10335 to reduce the bound corrinoid of MV8465 from a Co(II) to a $\mathrm{Co}(\mathrm{I})$ state. MV8465 was partially reduced to the $\mathrm{Co}$ (II) form with excess $\mathrm{Ti}$ (III)-citrate to a stabilized absorbance spectrum, consistent with the corrinoid being in the Co(II) state (Kreft and Schink, 1993) (Figure 6B). The addition of MV10335 resulted in a significant increase at $386 \mathrm{~nm}$, indicative of the $\mathrm{Co}(\mathrm{I})$ state. Following reduction of MV8465 by MV10335 we added MV8460 and GB as the methyl donor, which resulted in an observed decrease at $386 \mathrm{~nm}$ with a concomitant increase at $540 \mathrm{~nm}$ (Figure 6B).

\section{MV10360 Methylcob(III)alamin:CoM Activity}

The penultimate step to methanogenesis is the methylation of CoM, and achievement of this step in the TMA degradation pathway is through methylcob(III)alamin:CoM methyltransferase (Mt $x$ A) (Ferguson et al., 1996; Ferguson and Krzycki, 1997). CoM methylase activity of MV10360 was confirmed by monitoring change at $540 \mathrm{~nm}$. The specific activity of the recombinant MV10360 under the conditions tested was $1.6 \mu \mathrm{mol} \mathrm{min} \mathrm{mg}^{-1}$. Cob(II)alamin is generated during methylcob(III)alamin:CoM methyl transfer, causing a decrease at $540 \mathrm{~nm}$ (Ferguson et al., 2011; Supplementary Figure S2).

\section{GB:CoM Reconstitution and Methanogenesis Assays}

Following enzymatic confirmation of individual enzyme activities (MV8460, MV10335, and MV10360) predicted to be involved 


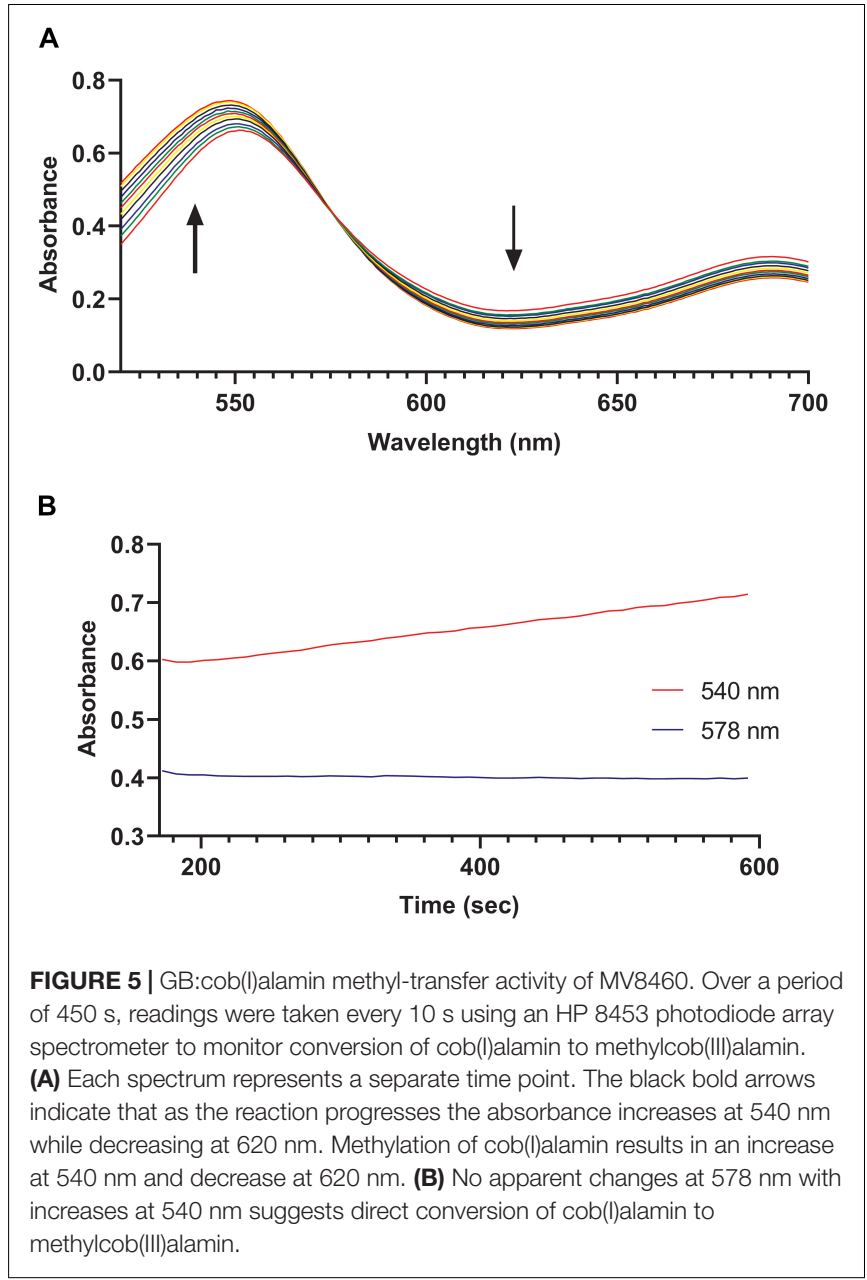

in the proposed GB:CoM pathway, we tested our hypothesis that GB-dependent methanogenesis occurs through a corrinoiddependent methyl transfer pathway initiated via MV8460. We successfully reconstituted GB:CoM methyl transfer using highly purified recombinant proteins (Figure 7 and Supplementary Figure S6). MV8460, MV8465, MV10335, and MV10360 are each required for methylation of CoM. No CoM methylation was detected when using choline, QMA, or TMA as methyl donors.

To confirm that the activity we observed was not an artifact of recombinant proteins, we performed in vitro GB:CoM activity assays using crude lysates from B1d (Supplementary Figure S3). Extracts from GB-grown cells methylated CoM when GB was the methyl donor, at a rate of $0.27 \mathrm{umol} \mathrm{min}^{-1} \mathrm{mg}^{-1}$, but not with TMA or methanol. Extracts from TMA-grown cells methylated CoM when TMA was the methyl donor, at a rate of $0.31 \mu \mathrm{mol} \mathrm{min}{ }^{-1} \mathrm{mg}^{-1}$, but not with GB, choline, or methanol. Surprisingly, CoM methylation was undetectable in extracts from methanol-grown cells using methanol, TMA, or GB as methyl donors, despite the extracts having been prepared identically to extracts of GB- or TMA-grown cells. The lower limit of detection for this assay was a loss of $0.3 \mathrm{mM}$ free CoM over the course of a $40 \mathrm{~min}$ assay.

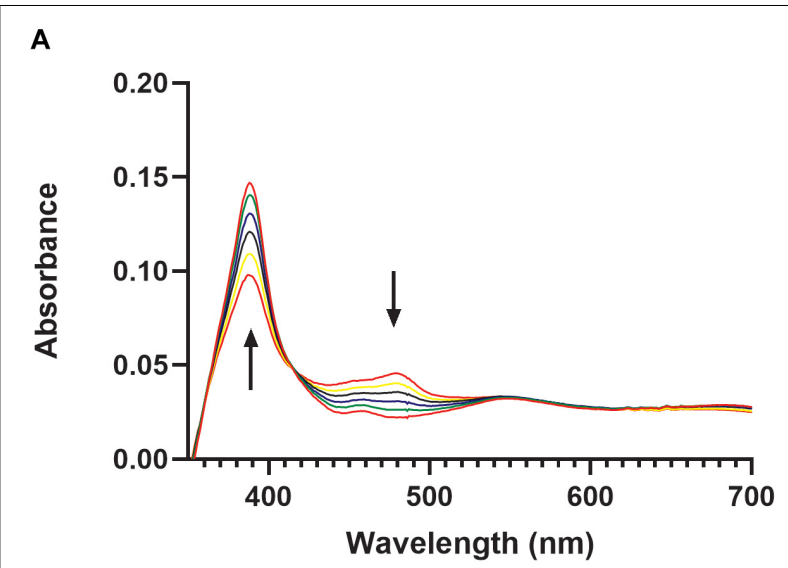

B

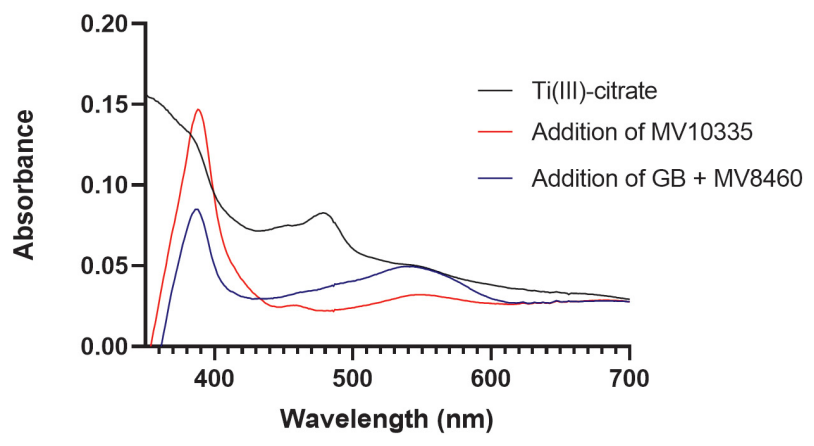

FIGURE 6 | Reductive activation of MV8465 by MV10335. In order for methylotrophic methanogenesis pathways to function, the corrinoid binding protein must be in the active $\mathrm{Co}(\mathrm{l})$ state. MV10335 functions to reduce MV8465 to this active state. Ti(III)-citrate serves as an electron source for MV10335 but can also reduce MV8465 to $\mathrm{Co}(\mathrm{II})$, and therefore was added prior to the addition of MV10335. (A) Each spectrum is a time point with the black arrows indicating an increase absorbance at $378 \mathrm{~nm}$ and a decrease in absorbance at $478 \mathrm{~nm}$, which is characteristic of reduction from $\mathrm{Co}(\mathrm{II})$ to $\mathrm{Co}(\mathrm{I})$. (B) MV8465 was initially reduced to Co(II) by Ti(III)-citrate to a stabilized spectrum (black line) and was then reduced to a Co(I) by the addition of MV10335 (red line). The major peak seen at $386 \mathrm{~nm}$ is characteristic of a Co(I) species. Addition of MV8460 and GB resulted in a decrease at $386 \mathrm{~nm}$ and an increase at $540 \mathrm{~nm}$ (blue line) indicating the formation of methylcob(III)alamin.

Extracts prepared from B1d cells grown on GB, TMA, or methanol lacked detectable methanol:CoM activity, we therefore tested for methanogenesis from prepared live cells, following previously established methods (Tallant and Krzycki, 1997). Washed cells grown on GB, TMA, or methanol showed rapid methane production when provided the same substrate, but a lag was detected if the cells were provided a different substrate (data not shown).

\section{MtaB Modeling}

Due to the presence of MV10350 during growth on GB (Figure 1A and Supplementary Figure S1A), we modeled MV10350 to determine if GB could fit into the catalytic active site (Supplementary Figure S4). MV10350 shares $72.77 \%$ sequence identity and $99 \%$ query coverage with $M$. barkeri Fusaro MtaB (UniProtKB - Q46EH3). I-TASSER generated a homology model 


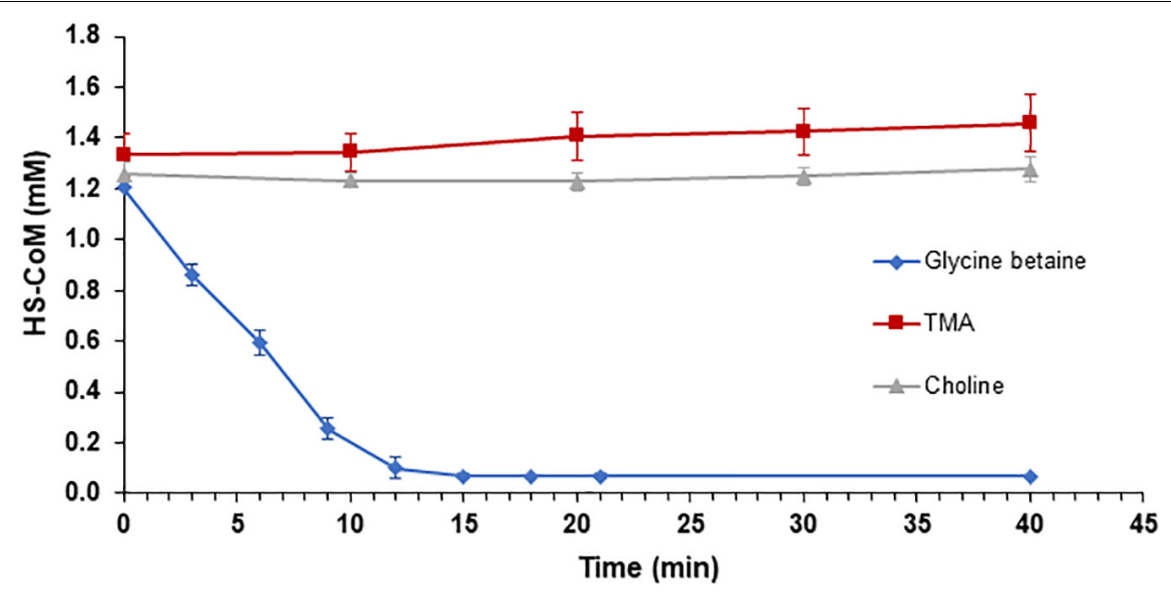

FIGURE 7 | Reconstitution of GB:CoM activity in vitro with purified recombinant proteins. Loss of the free thiol group on CoM was monitored at 412 nm, using Ellman's reagent. Addition of GB resulted in a significant decrease in the amount of HS-CoM that is detectable (blue diamond), indicating an intact GB:CoM methyl transfer pathway. Methylation of CoM was not detectable when TMA (red square) or choline (gray triangle) served as the methyl donors. The assays contained $10 \mu \mathrm{g}$ of MV8460 and $5 \mu \mathrm{g}$ each of the remaining proteins. Assays in which MV8460, MV8465, MV10335, or MV10360 were omitted lacked GB:CoM activity (data not shown). Error bars represent standard deviations $(n=3)$.

of MV10350 with a C-score (2), TM-score (0.99 \pm 0.03$)$, and $\operatorname{RMSD}(2.5 \pm 1.9 \AA)$ to M. barkeri MtaB (PDB - 2I2X) (Hagemeier et al., 2006) (Supplementary Figure S4A). We used the proposed active site motif of MtaB (Supplementary Figure S4B) for predictive docking of methanol and GB to MV10350. The hydroxyl-group of methanol is located either near zinc, C219 or E312 in MV10350 (Hagemeier et al., 2006). Attempts to dock GB resulted in poor ligand positioning to cobalamin or steric hindrance due to zinc or the proposed potassium ion. Key residues involved with cation- $\pi$ interactions for quaternary amine interactions are also lacking in MV10350 and therefore we could not accurately model GB into the active site of this enzyme.

\section{DISCUSSION}

Methanogenesis by B1d from GB as the sole carbon source results in approximately $0.75: 1$ stoichiometry of methane produced to GB consumed (Ticak et al., 2015). This suggested initial breakdown of GB is through a single demethylation reaction and not through the Stickland reaction that results in the formation of TMA and requires a betaine reductase (not present in the B1d draft genome) (Naumann et al., 1983). This work reports in vitro reconstitution of the methylotrophic GB:CoM pathway from B1d. Our work is consistent with published work on QMAdependent methanogenesis (Asakawa et al., 1998), but expands it to include the identities of the genes encoding the enzymes of the pathway, the involvement of a Pyl-lacking COG5598 enzyme, and focuses on a likely more ecologically relevant QA. Our work is also consistent with a recently published study showing the involvement of another Pyl-lacking COG5598 enzyme and cognate corrinoid binding protein during methylotrophic growth of the gut bacterium Eubacterium limosum on the QA proline betaine (Picking et al., 2019). Given our results, we propose the following model for metabolism of GB from B1d (Figure 8).
Amongst the compounds tested, MV8460 appeared to only interact with GB, which is consistent with previous work on methylotrophic methyltransferases (Burke and Krzycki, 1995; Ferguson and Krzycki, 1997; Sauer et al., 1997; Sauer and Thauer, 1998; Ferguson et al., 2000; Tallant et al., 2000; Pritchett and Metcalf, 2005; Ticak et al., 2014). In-depth analysis of the biochemical interactions between MV8460 and MV8465 was beyond the scope of this work and therefore we did not determine if MV8460 could interact with another corrinoid binding protein from a different methylotrophic pathway. However, productive interaction of methylotrophic methyltransferases with noncognate corrinoid binding proteins has never been reported, to our knowledge. Therefore, interaction of MV8460 with another corrinoid protein seems unlikely.

Until recently, the only characterized Pyl-lacking COG5598 homolog was from D. hafniense Y51 and it functions to demethylate GB (Ticak et al., 2014). The high similarity between MV8460 and DhMtgB coming from different domains of life piqued our interest to search for conserved amino acids and model DhMtgB and MV8460 for basic analysis of the catalytic pocket and docking of GB (Figure 4). Interestingly, in many of the crystal structures of enzymes which bind GB or other quaternary amines (Schiefner et al., 2004; Horn et al., 2006; Wolters et al., 2010; Salvi et al., 2014; Li et al., 2015), the methyl moiety is commonly flanked with aromatic compounds which are involved in cation- $\pi$ and $\pi-\pi$ stacking. The residues likely involved with either cation- $\pi$ or $\pi-\pi$ stacking are Y94 and F353/Y353 while the interaction of H345 is more complex. Given physiological $\mathrm{pH}$ and the $\mathrm{pKa}$ of histidine, H345 is likely protonated and acts as a hydrogen donor to the carboxyl moiety of GB much like 4MJW (Salvi et al., 2014). Additionally, given the distance (4.1 $\AA$, DhMtgB; $4.6 \AA$, MV8460) and the positioning of $\mathrm{H} 345$ it is unlikely to interact in cation- $\pi$ with the methyl moiety. It is more likely that $\mathrm{H} 345$ would be involved in $\pi-\pi$ stacking with the nearby F353/Y353 if H345 was unprotonated. 


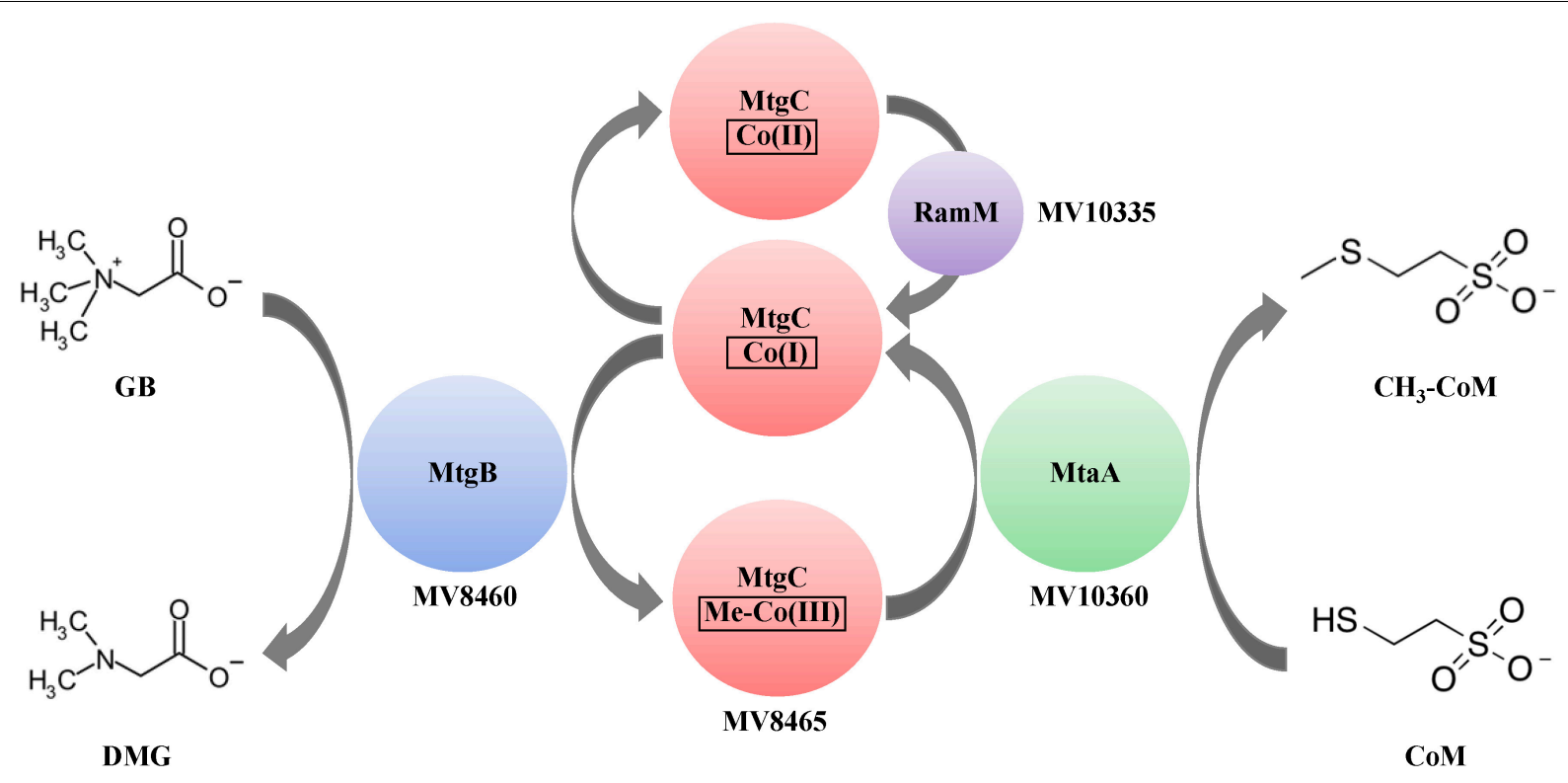

FIGURE $\mathbf{8}$ | Proposed model of GB-dependent CoM methylation. Proteins are represented by colored circles/ovals and locations of genes that encode for them are also represented. The first methyltransferase, MtgB (blue), is a Pyl-lacking member of the COG5598 superfamily. MtgB catalyzes transfer of a methyl group from GB to the cognate corrinoid-binding protein, MtgC (red). The second methyltransferase, MtaA (green), catalyzes methyl transfer from Me-MtgC to CoM. The corrinoid reductive activation enzyme, RamM (purple), reduces the bound corrinoid of MtgC, when required. DMG is dimethylglycine.

The position of GB within the predicted funnel would also involve R309 for positioning of the carboxylic moiety in both DhMtgB and MV8460 for helping coordinate the molecule and methyl group for catalytic attack by the $\mathrm{Co}(\mathrm{I})$ species from MV8465. This positioning of the methyl group for catalytic attack is analogous to what has been seen previously in MtaBC (Hagemeier et al., 2006).

The proteomic data revealed constitutive production of the proteins involved in methanol-dependent methanogenesis (Figure 1), at varying levels depending on the substrate. This suggests that methanol could be B1d's most commonly available carbon source in the environment, which would make it advantageous for the organism to maintain production of the enzymes under all conditions. Interestingly, we could not detect methanol:CoM methyl transfer activity in any of our extracts. Therefore, we considered the possibility that the putative MtaB, MV10350, could be involved with GB metabolism. The MtaB from $M$. barkeri forms a tight complex with MtaC and supporting evidence suggests this complex is only active for methanol degradation (Sauer et al., 1997; Sauer and Thauer, 1998; Pritchett and Metcalf, 2005; Hagemeier et al., 2006). Additionally, our methanogenesis assays on methanol grown cells when they were fed GB showed no apparent activity within a 24 min assay (data not shown), indicating that the intact methanol pathway did not readily interact with GB. Therefore, we suggest that if interactions between MV10350 and GB were possible, it would not be active at biologically relevant levels. MV10350 and MV8460 are not homologous and our modeling data of MV10350 using the crystal structure of the M. barkeri MtaB (Hagemeier et al., 2006) as a guide, suggests that GB would not fit into the catalytic pocket of MV10350 (Supplementary Figure S4).
Given the homology between MtgB and MttB, we predicted the involvement of a RamA and MtbA in the GB pathway. However, given that MtaA from the methanol pathway from $M$. barkeri can function in the methanogenesis pathway for TMA (Ferguson et al., 1996; Ferguson and Krzycki, 1997), it is not surprising that MV10335 (RamM) and MV10360 (MtaA) are used during methanogenesis from GB in B1d. The genetic regulation of the methanol operon that encodes these two enzymes is not currently known and may be subject to future study. In available methanogen genomes, the first methyltransferase of methylotrophic pathways is consistently encoded adjacent to its cognate corrinoid binding partner (Galagan et al., 2002; Maeder et al., 2006; Webster et al., 2019). It is interesting to speculate that methylotrophic methanogenic metabolism of GB, or potentially other QAs, could be achieved with the acquisition of two genes that encode a methyltransferase and a cognate corrinoid binding partner, yet methanogenic pathways for other QAs as direct carbon sources have yet to be established. The methylotrophic methanogenic pathway for GB is now known, and in Bld it involves two proteins associated with a methanol methanogenic pathway. Many microorganisms in brackish or marine environments utilize GB transporters to internalize GB for osmoprotection or biosynthesis (Ticak et al., 2014, 2015). Therefore, in nutritionally depleted environments due to competition, an advantage may be gained by the acquisition of genes encoding the enzymes for GB methylotrophy. This suggests a role for horizontal gene transfer with these forms of metabolism and potentially explains the clustering of the Pyl-lacking COG5598 enzymes from the GButilizing B1d and SLH33(T) archaea in a bacterial dominated clade (Figure 3B). 


\section{MATERIALS AND METHODS}

\section{Archaeal Strains, Media, and Growth}

B1d was routinely cultivated under strict anaerobic conditions in brackish medium using either glycine betaine (GB) $(80 \mathrm{mM})$, methanol (62.5 mM), or trimethylamine (TMA) (40 mM) (Ticak et al., 2015). Methanosarcina acetivorans WWM73 (WWM73) was a generous gift from Dr. William W. Metcalf (University of Illinois) and routinely cultivated using highsalt medium with methanol $(62.5 \mathrm{mM})$ and acetate $(40 \mathrm{mM})$ (Metcalf et al., 1997).

\section{Proteomics Analysis}

Mid-log phase B1d grown on either GB (80 mM), methanol $(62.5 \mathrm{mM})$, or trimethylamine $(40 \mathrm{mM})$ was used for proteomics analysis following similarly to previously described methods (Ticak et al., 2015). Anoxically harvested cell pellets were resuspended in $12 \mathrm{~mL}$ of buffer $\left(50 \mathrm{mM}\right.$ Tris- $\mathrm{HCl}, 10 \mathrm{mM} \mathrm{CaCl}_{2}$, $0.1 \% n$-Dodecyl $\beta$-D-maltoside, $\mathrm{pH} 7.6$ ), followed by cell lysis by French press, as described below. Cell lysates were centrifuged at $40,000 \times g$ for $45 \mathrm{~min}$ at $4^{\circ} \mathrm{C}$ and the supernatants were collected and used for proteomic analysis. Protein concentrations of the supernatants were measured using the Bradford assay (Bradford, 1976) (Thermo Scientific).

For each sample, $100 \mu \mathrm{g}$ of total protein was denatured in $8 \mathrm{M}$ urea supplemented with $5 \mathrm{mM}$ dithiothreitol. The protein solution was diluted to $2 \mathrm{M}$ urea using the same Tris buffer, followed by a 1:100 w/w Trypsin Gold (Promega) protein digestion at $37^{\circ} \mathrm{C}$ for $18 \mathrm{~h}$. Digested peptides were desalted using Sep-Pak C18 columns following the manufacturer's protocol (Waters Corporation), followed by peptide fractionation using a Pierce High $\mathrm{pH}$ Reverse-Phase Peptide Fractionation Kit (Thermo Scientific). Eight peptide fractions of each sample were separated using a capillary C18 column on an EASYnLC 1000 liquid chromatograph coupled to a Thermo LTQ Orbitrap XL mass spectrometer for MS analysis. The peptides were scanned in the range of $350-1800 \mathrm{~m} / \mathrm{z}$ at a resolution of 30,000 operating in the data-dependent mode. For each scan, the 12 most abundant peaks were selected and subjected to MS/MS analysis by collision induced dissociation fragmentation. The peptide identities were searched against a B1d database (Genbank accession number VIAQ00000000) using pipeline programs integrated in PatternLab for Proteomics (version 4.1.0.17) and normalized spectral abundance factor (NSAF) was used to compare protein abundances. Raw data and the searched sqt files have been deposited to the MassIVE repository with the identifier MSV000084013.

\section{Cloning and Expression Vectors}

B1d genomic DNA (gDNA) was extracted using phenolchloroform (Sambrook et al., 1989) and the gene encoding MV8460 was amplified using primers shown in Supplementary Table S2. The product was digested with SacII and XhoI (NEB) and treated with calf-intestinal alkaline phosphatase (NEB) before ligation into pASK-IBA43(+) (IBA Life Sciences) using T4-Ligase (NEB) to yield pASK_MV8460. The construct was maintained in Escherichia coli DH5 $\alpha$. The cloning of pASK_MV10335 followed similarly to pASK_MV8460.

The expression vector pET28(+) (Addgene) was modified to have a larger multiple cloning site. A DNA fragment containing an E. coli BL21(DE3) codon optimized version of the gene encoding MV10360 was purchased from Genscript in pUC57 and contained flanking restriction sites (Supplementary Figure S5). The fragment was removed from pUC57 via restriction digest with NcoI and BamHI (NEB) and ligated into pET28(+) yielding pET28_MV10360_Opt. The optimized MV10360 gene was removed from pET28_MV10360_Opt using DraI and PmlI (NEB) and the vector re-ligated, resulting in pETAC17a. The optimized MV10360 fragment was solely used as a tool to generate pETAC17a, however, the optimized gene was not used in our experiments. The gene encoding MV10360 was amplified from B1d gDNA before cloning into pETAC17a yielding pETAC_MV10360.

Cloning of MV8465 into pDL05c followed established methods (Longstaff et al., 2007) using the MV8465 + AsisI F and MV8465 + Tev R primers (Supplementary Table S2). A second amplification using MV8465 + AsisI F and Tev + His R added a $3^{\prime}$ hexahistidine tag. The fragment was digested with XhoI and SacII and ligated into pDL03c yielding pDLAC03_MV8465 before cloning into pDL05c resulting in pDLAC05_MV8465 and was maintained in E. coli EC100 cells. Transformation into WWM73 followed previously established methods (Ladapo and Whitman, 1990; Metcalf et al., 1997).

\section{Production of Recombinant Proteins}

Production of MV8460 followed similarly to established methods (Ticak et al., 2014). Anhydrous tetracycline (1 mg/L) was used to induce protein production. E. coli ArcticExpress (Agilent) was used to produce MV10360, following manufacturer's protocol with modifications. Following the initial growth period prior to induction, cells were chilled at $4^{\circ} \mathrm{C}$ for $3 \mathrm{~h}$. Cells were induced with $1 \mathrm{mM}$ isopropyl $\beta$-D-1-thiogalactopyranoside (IPTG) and incubated at $10^{\circ} \mathrm{C}$ shaking at $125 \mathrm{RPM}$ for $24 \mathrm{~h}$. All cells were harvested by centrifugation at 7,500 $\times g$ for $15 \mathrm{~min}$ at $4^{\circ} \mathrm{C}$ and cell pellet stored at $-80^{\circ} \mathrm{C}$.

Production of MV10335 was done under anoxic conditions using E. coli SG13009, a gift from Dr. Joseph Krzycki (The Ohio State University). Cells were grown in anoxic LB supplemented with sodium phosphate $(44 \mathrm{mM})$ prior to autoclaving and glucose $(80 \mathrm{mM})$ and fumarate $(80 \mathrm{mM})$ after autoclaving. The medium was bubbled with pure $\mathrm{N}_{2}$ for $30 \mathrm{~min}$, after sterilization, then the flask was quickly stoppered and secured with copper wire. Additionally, $160 \mathrm{~mL}$ serum bottles were prepared containing $42 \mathrm{~mL}$ of the amended LB medium and made anoxic by stoppering the top and flushed and evacuated using $\mathrm{N}_{2}$, then sterilized by autoclaving and amended with glucose and fumarate. Starter cultures $(50 \mathrm{~mL})$ were grown statically overnight at $34^{\circ} \mathrm{C}$. Starter cultures were transferred to the amended $\mathrm{LB}$ and grown at $34^{\circ} \mathrm{C}$ shaking at $125 \mathrm{RPM}$ to an $\mathrm{OD}_{600}$ between 0.3 and 0.4 and then supplemented with cysteine $(5 \mathrm{mM})$ and ferrous ammonium chloride $(0.1 \mathrm{mM})$. Production was induced with IPTG $(1 \mathrm{mM})$ followed by a $6 \mathrm{~h}$ incubation at $34^{\circ} \mathrm{C}$ shaking at $125 \mathrm{RPM}$. Cysteine and ferrous ammonium 
chloride were added again after $6 \mathrm{~h}$ incubation and the culture was further incubated for $2 \mathrm{~h}$. Cells were harvested anoxically, as described above.

MV8465 production was done in WWM73 (Longstaff et al., 2007). Cells producing MV8465 were grown in 1-L of highsalt mineral media. The medium mixes $\mathrm{A}$ and $\mathrm{B}$ were prepared and autoclaved separately, mixed, and then amended with methanol $(62.5 \mathrm{mM})$, acetate $(40 \mathrm{mM})$, ampicillin $(100 \mu \mathrm{g} / \mathrm{L})$, and puromycin $(2 \mu \mathrm{g} / \mathrm{L})$. The medium was supplemented anoxically with filter sterilized: $\mathrm{KH}_{2} \mathrm{PO}_{4}(5 \mathrm{mM})$, cysteine- $\mathrm{HCl}$ (2.8 $\mathrm{mM})$, ammonium chloride $(19 \mathrm{mM})$, and $\mathrm{Na}_{2} \mathrm{~S}(0.4 \mathrm{mM})$. A 5\% (v/v) inoculum of WWM73 pDL05cMV8465 was grown statically at $37^{\circ} \mathrm{C}$ to $\mathrm{OD}_{600} \sim 0.5$ and transferred to the $1-\mathrm{L}$ of high-salt media. The culture was grown statically at $37^{\circ} \mathrm{C}$ to stationary phase with periodic venting. Cells were harvested as described above.

\section{Protein Purification}

Purification of His-tagged MV8460, MV10360, and MV8465 was done using established methods (Ticak et al., 2014), with additional steps. All proteins were partially purified anoxically using a HisTrap ${ }^{\mathrm{TM}} \mathrm{HP}$ using an ÄKTA Prime Plus (GE Healthcare). Lysates were loaded onto $1 \mathrm{~mL}$ columns and equilibrated with anoxic 95\% Buffer A and 5\% Buffer B (Ticak et al., 2014) for 10 column volumes and subjected to a 50$\mathrm{mL}$ linear gradient from $5 \%$ to $100 \%$ Buffer $\mathrm{B}$ at $1 \mathrm{~mL} / \mathrm{min}$. MV8460, MV8465, and MV10360 each eluted as single peaks at $80-175,85-145$, and $65-145 \mathrm{mM}$ imidazole, respectively. Protein peaks were pooled and diluted 1:5 with Buffer C (20 mM MOPS, $0 \mathrm{M} \mathrm{NaCl}, \mathrm{pH}$ 7.8). Samples were loaded onto $1-\mathrm{mL}$ Bio-Scale ${ }^{\mathrm{TM}}$ Mini UNOsphere ${ }^{\mathrm{TM}} \mathrm{Q}$ cartridges (BIO-RAD) and equilibrated with 10 column volumes of Buffer $\mathrm{C}$ followed by a 0 to $70 \%$ Buffer D (20 mM MOPS, $1 \mathrm{M} \mathrm{NaCl}, \mathrm{pH} 7.8$ ) linear gradient. MV8460, MV8465, and MV10360 each eluted as single peaks at 330-420 mM, 240-430 mM, and 300-500 mM NaCl, respectively. MV8465 was diluted 1:5 with Buffer E (5 mM sodium phosphate, $\mathrm{pH} 7.0$ ), loaded onto a $5-\mathrm{mL}$ Bio-Scale Mini CHT Type I Cartridge (BIO-RAD), and equilibrated with 5 column volumes of Buffer $\mathrm{E}$ followed by a $0 \%$ to $100 \%$ Buffer $\mathrm{F}$ (500 mM sodium phosphate, $\mathrm{pH}$ 7.0) linear gradient following the manufacturer's protocol. MV8465 eluted from the CHT column in a single peak at 185-210 mM phosphate. Protein purity was assessed via SDS-PAGE (BIO-RAD) followed by Coomassie blue staining (Supplementary Figure S6). Protein concentrations were determined by the Bradford protein assay (Bradford, 1976) and frozen at $-20^{\circ} \mathrm{C}$. Proteins were used within 6 months of freezing.

Materials needed for MV10335 purification were made anoxic 3 days prior to use. The cell pellet was resuspended in anoxic Buffer A and lysed via an anoxically adapted French press cell at 20,000 PSI. The anoxic lysate was spun at $250,000 \times g$ at $4^{\circ} \mathrm{C}$ for $1.5 \mathrm{~h}$, and then passed through a $0.22 \mu \mathrm{m}$ syringe filter. MV10335 was purified as described above. MV10335 eluted as a single peak at $77-175 \mathrm{mM}$ imidazole and as a single peak at $280-420 \mathrm{mM} \mathrm{NaCl}$. Fractions were filtered into an anoxic Wheaton serum bottle. MV10335 degrades upon freeze-thaw cycles and therefore was stored at $4^{\circ} \mathrm{C}$ and used within 5 days after purification.

\section{MV8460 and MV10360 Methyltransferase Activity}

Assays monitoring the activity of MV8460 followed described methods measuring the change at 540 and $578 \mathrm{~nm}$ at $37^{\circ} \mathrm{C}$ (Ticak et al., 2014). The reaction contained $50 \mu \mathrm{g}$ (950 pmol) MV8460 and was initiated by addition of a methyl donor (50 mM). Measurements were taken every $10 \mathrm{~s}$ for 450 s. MV10360 activity assays followed described methods (Ferguson et al., 2011). Methylcob(III)alamin $(595 \mu \mathrm{L})$ and CoM $(5 \mu \mathrm{L})$ were added to an anoxic cuvette and incubated at $37^{\circ} \mathrm{C}$ for $10 \mathrm{~min}$. The reaction was initiated by addition of $50 \mu \mathrm{g}$ MV10360 and monitored until no detectable change at $540 \mathrm{~nm}$.

\section{Reductive Activation of MV8465 by MV10335 Followed by Methylation of MV8465 by MV8460}

Monitoring reduction of MV8465 followed described methods described (Ferguson et al., 2009). Reaction mixtures were assembled in sealed anoxic $0.2 \mathrm{~cm}$ cuvettes containing $12.5 \mathrm{mM}$ ATP, $25 \mathrm{mM} \mathrm{MgCl}_{2}$, $4 \mathrm{mM} \mathrm{Ti(III)-citrate,} \mathrm{MV8465} \mathrm{(800} \mathrm{\mu g/ml),}$ and $50 \mathrm{mM}$ MOPS, $\mathrm{pH} 7.2$. Reactions were incubated at $37^{\circ} \mathrm{C}$ monitoring change at $378 \mathrm{~nm}$ until the spectrum stabilized. MV10335 $(216.5 \mu \mathrm{g} / \mathrm{ml})$ was added and the $400 \mathrm{uL}$ reaction was incubated for $45 \mathrm{~min}$ monitoring the change at 378 and $475 \mathrm{~nm}$ every $2 \mathrm{~min}$. Upon stabilization of the spectrum, $3.75 \mu \mathrm{l}$ each of MV8460 $(144 \mu \mathrm{g} / \mathrm{ml})$ and GB $(18.75 \mathrm{mM})$ were added and the cuvette incubated for $30 \mathrm{~min}$ taking measurements every $2 \mathrm{~min}$.

\section{In vitro Reconstitution of GB:CoM Methyl Transfer Pathway}

Testing for functionality of individual proteins that were used for in vitro reconstitution of the GB:CoM pathway followed similarly to established methods and are summarized above and in Supplementary Material. All assays were performed as previously described (Ferguson et al., 2009, Ferguson et al., 2011; Ticak et al., 2014), with minor modifications. A 5x reaction mixture containing CoM (15 mM), ATP (62.5 mM), and $\mathrm{MgCl}_{2}$ $(125 \mathrm{mM})$ was prepared in $50 \mathrm{mM}$ MOPS, $\mathrm{pH}$ 7.2. The assay was performed in a stoppered anoxic cuvette with a final reaction volume of $250 \mu \mathrm{L}$. Ti(III)-citrate (Seefeldt and Ensign, 1994; Ferguson et al., 2011) amended MOPS was added followed by

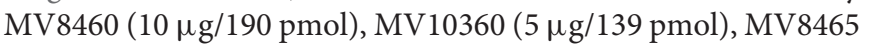
(5 $\mu \mathrm{g} / 174 \mathrm{pmol}), \mathrm{MV} 10335$ (5 $\mu \mathrm{g} / 85 \mathrm{pmol})$, and the reaction mixture. Ten $\mu \mathrm{L}$ of $\mathrm{Ti}(\mathrm{III})$-citrate $(\sim 4 \mathrm{mM})$ was added as a source of reducing potential and the cuvette incubated at $37^{\circ} \mathrm{C}$ for $45 \mathrm{~min}$. The reaction was initiated by adding $10 \mu \mathrm{L}$ of the methyl donor (16 mM). Samples were taken every $4 \mathrm{~min}$ for $24 \mathrm{~min}$ and mixed with Ellman's reagent (Ellman, 1958) in a 96-well round bottom plate and measured at $412 \mathrm{~nm}$ using a MolDev FilterMax F5 plate reader. The lower limit of detection for free CoM with Ellman's reagent, in our hands, is a loss of $0.3 \mathrm{mM}$ free CoM over the course of a 40 min assay. 


\section{Methanolobus vulcani B1d Substrate Dependent CoM Methylation in Extracts}

B1d cells were grown either on GB, methanol, or TMA and anoxically harvested during mid-log phase (Ticak et al., 2015). Cells were resuspended with anoxic MOPS (50 mM), pH 7.2 and anoxically lysed, as described above. Lysed cells were centrifuged, and lysates were filtered into sterilized anoxic serum bottles, as described above, and headspace exchanged with $\mathrm{H}_{2}$. The assay followed similarly to previously established methods (Ferguson et al., 2011). Ti(III)-citrate ( $\sim 4 \mathrm{mM})$ and a headspace of $\mathrm{H}_{2}$ were both required for substrate demethylation activity.

\section{Sequence Acquisition and Phylogenetic Construction of MttB Superfamily}

The DhMtgB amino acid (aa) sequence (UniProtKB-Q24SP7) was used as a query with PSI-BLAST (Altschul et al., 1997) with a $1 \mathrm{E}^{-10}$ cutoff, for the non-redundant protein sequence (nr) database. Similarly, the MttB of M. barkeri (UniProtKB O93658) was used to acquire Pyl-encoding MttB sequences via tBLASTn (Gertz et al., 2006). Sequences varying more than one standard deviation from the mean aa length and those with identities less than $30 \%$ of the query were removed. The remaining 5517 sequences were filtered using $\mathrm{CD}$-Hit ( $\mathrm{Li}$ and Godzig, 2006) to remove those with greater than $90 \%$ identity providing a final dataset of 2356 sequences averaging 504 aa. MV8460 and MttB10 (UniProtKB - H6LKF8) were added to the dataset from B1d and Acetobacterium woodii, respectively. The dataset was aligned with MUSCLE (Edgar, 2004) using default settings. Phylogenetic analysis was performed using approximately maximum-likelihood with FastTree 2 (Price et al., 2010), using JTT + CAT (Jones et al., 1992), WAG + CAT (Whelan and Goldman, 2001), and LG + CAT (Le and Gascuel, 2008), with and without Gamma distribution. Phylogenetic trees were generated using the interactive Tree of Life (iTOL) (Letunic and Bork, 2016).

\section{Homology Modeling Prediction of MV8460 and Molecular Docking of Glycine Betaine}

The apo-structure of DhMtgB chain A (PDB - 2QNE) was used as a template to generate two models of MV8460 using both MODELLER (Webb and Sali, 2017) and I-TASSER (Zhang, 2008) for comparison. MetaPocket 2.0 (Huang, 2009) was used to predict possible binding site(s) for GB in DhMtgB and MV8460.

\section{REFERENCES}

Altschul, S. F., Madden, T. L., Schaffer, A. A., Zhang, J., Zhang, Z., Miller, W., et al. (1997). Gapped BLAST and PSI-BLAST: a new generation of protein database search programs. Nucleic Acid Res. 25, 3389-3402. doi: 10.1093/nar/25.17.3389

Asakawa, S., Sauer, K., Liesack, W., and Thauer, R. K. (1998). Tetramethylammonium: coenzyme M methyltransferase system from Methanococcoides sp. Arch. Microbiol. 170, 220-226. doi: 10.1007/s0020300 50636

Auffret, M. D., Stewart, R., Dewhurst, R. J., Duthie, C. A., Rooke, J. A., Wallace, R. J., et al. (2017). Identification, comparison, and validation of robust rumen
Probably binding pockets and molecular docking predictions were performed using AutoDockTools and AutoDockVina, respectively (Trott and Olson, 2010).

Models with GB docked in the active site were visualized with PyMol v2.3. Aligned models were inspected for residues within 4-5 ^̊ from GB to identify proposed active site signatures, generated with WebLogo3 (Sharma et al., 2012).

\section{DATA AVAILABILITY STATEMENT}

The datasets generated for this study can be accessed from the Genbank accession number VIAQ00000000, MassIVE repository identifier MSV000084013.

\section{AUTHOR CONTRIBUTIONS}

AC, TT, XW, and DF were involved in the design, performance, analysis, and interpretation of the experiments and wrote the manuscript. SS was involved in performance of the experiments.

\section{FUNDING}

This work was supported by funding from the National Science Foundation (Award Number: 1818178) and the National Institutes of Health (Award Number: R01DK109345), as well as internal funding from Miami University.

\section{ACKNOWLEDGMENTS}

We thank Dr. Joe Krzycki for many valuable discussions. We acknowledge and thank the staff (Dr. Andor Kiss and Ms. Xiaoyun Deng) of the Center for Bioinformatics and Functional Genomics (CBFG) at Miami University for instrumentation and computational support.

\section{SUPPLEMENTARY MATERIAL}

The Supplementary Material for this article can be found online at: https://www.frontiersin.org/articles/10.3389/fmicb. 2019.02572/full\#supplementary-material

microbial biomarkers for methane emissions using diverse Bos taurus breeds and basal diets. Front. Microbiol. 8:2642. doi: 10.3389/fmicb.2017.02642

Borrel, G., O’Toole, P. W., Harris, H. M., Peyret, P., Brugere, J. F., and Gribaldo, S. (2013). Phylogenomic data support a seventh order of Methylotrophic methanogens and provide insights into the evolution of methanogenesis. Genome Biol. Evol. 5, 1769-1780. doi: 10.1093/gbe/ evt128

Bradford, M. M. (1976). A rapid and sensitive method for the quantification of microgram quantities of protein utilizing the principle of protein-dye binding. Anal. Biochem. 72, 248-254. doi: 10.1006/abio.1976. 9999 
Burke, S. A., and Krzycki, J. A. (1995). Involvement of the "A" isozyme of methyltransferase II and the 29-kilodalton corrinoid protein in methanogenesis from monomethylamine. J. Bacteriol. 177, 4410-4416. doi: 10.1128/jb.177.15. 4410-4416.1995

Craciun, S., and Balskus, E. P. (2012). Microbial conversion of choline to trimethylamine requires a glycyl radical enzyme. Proc. Natl. Acad. Sci. U.S.A. 109, 21307-21312. doi: 10.1073/pnas.1215689109

Dehning, I., Stieb, M., and Schink, B. (1989). Sporomusa malonica sp. nov., a homoacetogenic bacterium growing by decarboxylation of malonate or succinate. Arch. Microbiol. 151, 421-426. doi: 10.1007/bf00416601

Deng, J., McCalley, C. K., Frolking, S., Chanton, J., Crill, P., Varner, R., et al. (2017). Adding stable carbon isotopes improves model representation of the role of microbial communities in peatland methane cycling. J. Adv. Model. Earth Syst. 9, 1412-1430. doi: 10.1002/2016ms000817

Edgar, R. C. (2004). MUSCLE: multiple sequence alignment with high accuracy and high throughput. Nucleic Acids Res. 32, 1792-1797. doi: 10.1093/nar/gkh340

Ellman, G. L. (1958). A colorimetric method for determining low concentrations of mercaptans. Arch. Biochem. Biophys. 74, 443-450. doi: 10.1016/0003-9861(58) 90014-6

Enzmann, F., Mayer, F., Rother, M., and Holtmann, D. (2018). Methanogens: biochemical background and biotechnological applications. AMB Express 8:1. doi: 10.1186/s13568-017-0531-x

Ferguson, D. J. Jr., Gorlatova, N., Grahame, D. A., and Krzycki, J. A. (2000). Reconstitution of dimethylamine:coenzyme M methyl transfer with a discrete corrinoid protein and two methyltransferases purified from Methanosarcina barkeri. J. Biol. Chem. 275, 29053-29060. doi: 10.1074/jbc.m910218199

Ferguson, D. J. Jr., and Krzycki, J. A. (1997). Reconstitution of trimethylaminedependent coenzyme M methylation with the trimethylamine corrinoid protein and the isozymes of methyltransferase II from Methanosarcina barkeri. J. Bacteriol. 179, 846-852. doi: 10.1128/jb.179.3.846-852.1997

Ferguson, D. J. Jr., Krzycki, J. A., and Grahame, D. A. (1996). Specific roles of methylcobamide:coenzyme $\mathrm{M}$ methyltransferase isozymes in metabolism of methanol and methylamines in Methanosarcina barkeri. J. Biol. Chem. 271, 5189-5194. doi: 10.1074/jbc.271.9.5189

Ferguson, D. J. Jr., Longstaff, D. G., and Krzycki, J. A. (2011). Assay of methylotrophic methyltransferases from methanogenic archaea. Methods Enzymol. 494, 139-158. doi: 10.1016/B978-0-12-385112-3.00008-1

Ferguson, T. K., Soares, J. A., Lienard, T., Gottschalk, G., and Krzycki, J. A. (2009). RamA, a protein required for reductive activation of corrinoid-dependent methylamine methyltransferase reactions in methanogenic archaea. J. Biol. Chem. 284, 2285-2295. doi: 10.1074/jbc.M807392200

Ferry, J. G. (2011). Fundamentals of methanogenic pathways that are key to the biomethanation of complex biomass. Curr. Opin. Biotechnol. 22, 351-357. doi: 10.1016/j.copbio.2011.04.011

Finster, K., Liesack, W., and Tindall, B. J. (1997). Desulfospira joergensenii, gen. nov., sp. nov., a new sulfate-reducing bacterium isolated from marine surface sediment. Syst. Appl. Microbiol. 20, 201-208. doi: 10.1016/s0723-2020(97) 80066-5

Galagan, J. E., Nusbaum, C., Roy, A., Endrizzi, M. G., Macdonald, P., FitzHugh, W., et al. (2002). The genome of Methanosarcina acetivorans reveals extensive metabolic and physiological diversity. Genome Res. 12, 532-542. doi: 10.1101/ gr.223902

Gertz, E. M., Yi-Kuo, Y., Agarwala, R., Schäffer, A. A., and Altschul, S. F. (2006). Composition-based statistics and translated nucleotide searches: improving the TBLASTN module of BLAST. BMC Biol. 4:41. doi: 10.1186/1741-7007-4-41

Hagemeier, C. H., Krer, M., Thauer, R. K., Warkentin, E., and Ermler, U. (2006). Insight into the mechanism of biological methanol activation based on the crystal structure of the methanol-cobalamin methyltransferase complex. Proc. Natl. Acad. Sci. U.S.A. 103, 18917-18922. doi: 10.1073/pnas.0603650103

Hao, B., Gong, W., Ferguson, T. K., James, C. M., Krzycki, J. A., and Chan, M. K. (2002). A new UAG-encoded residue in the structure of a methanogen methyltransferase. Science 296, 1462-1466. doi: 10.1126/science.1069556

Horn, C., Sohn-Bösser, L., Breed, J., Welte, W., Schmitt, L., and Bremer, E. (2006). Molecular determinants for substrate specificity of the ligand-binding protein OpuAC from Bacillus subtilis for the compatible solutes glycine betaine and proline betaine. J. Mol. Biol. 357, 592-606. doi: 10.1016/j.jmb.2005. 12.085
Huang, B. (2009). metaPocket: a meta approach to improve protein ligand binding site prediction. OMICS 13, 325-330. doi: 10.1089/omi.2009.0045

Jones, D. T., Taylor, W. R., and Thornton, J. M. (1992). The rapid generation of mutation data matrices from protein sequences. Comput. Appl. Biosci. 8, 275-282. doi: 10.1093/bioinformatics/8.3.275

King, G. M. (1984). Metabolism of trimethylamine, choline, and glycine betaine by sulfate-reducing and methanogenic bacteria in marine sediments. Appl. Environ. Microbiol. 48, 719-725.

Kreft, J. U., and Schink, B. (1993). Demethylation and degradation of phenylmethylethers by the sulfide-methylating homoacetogenic bacterium strain TMBS 4. Eur. J. Biochem. 226, 945-951.

Krzycki, J. A. (2005). The direct genetic encoding of pyrrolysine. Curr. Opin. Microbiol. 8, 706-712. doi: 10.1016/j.mib.2005.10.009

Kuhner, C. H., Frank, C., Griesshammer, A., Schmittroth, M., Acker, G., Gössner, A., et al. (1997). Sporomusa silvacetica sp, nov., an acetogenic bacterium isolated from aggregated forest soil. Int. J. Syst. Evol. Microbiol. 47, 352-358. doi: 10.1099/00207713-47-2-352

Ladapo, J., and Whitman, W. B. (1990). Method for isolation of auxotrophs in the methanogenic archaebacteria: role of the acetyl-CoA pathway of autotrophic CO2 fixation in Methanococcus maripaludis. Proc. Natl. Acad. Sci. U.S.A. 87, 5598-5602. doi: 10.1073/pnas.87.15.5598

Le, S. Q., and Gascuel, O. (2008). An improved general amino acid replacement matrix. Mol. Biol. Evol. 25, 1307-1320. doi: 10.1093/molbev/ msn067

Lechtenfeld, M., Heine, J., Sameith, J., Kremp, F., and Müller, V. (2018). Glycine betaine metabolism in the acetogenic bacterium Acetobacterium woodii. Environ. Microbiol. 20, 4512-4525. doi: 10.1111/1462-2920.14389

Letunic, I., and Bork, P. (2016). Interactive tree of life (iTOL) v3: an online tool for the display and annotation of phylogenetic and other trees. Nucleic Acids Res. 44, W242-W245. doi: 10.1093/nar/gkw290

L'Haridon, S. M., Chalopin, M. M., Colombo, D. M., and Toffin, L. (2014). Methanococcoides vulcani sp. nov., a novel marine methylotrophic methanogen; using betaine, choline and N,N-dimethylethanolamine for methanogenesis, isolated from the napoli mud volcano in the eastern mediterranean Sea; and emendation of the genus Methanococcoides. Int J. Syst. Evol. Microbiol. 64, 1978-1983. doi: 10.1099/ijs.0.058289-0

Li, C. Y., Chen, X. L., Shao, X., Wei, T. D., Wang, P., Xie, B. B., et al. (2015). Mechanistic Insight into trimethylamine $\mathrm{N}$-oxide recognition by the marine bacterium Ruegeria pomeroyi DSS-3. J. Bacteriol. 197, 3378-3387. doi: 10.1128/ JB.00542-15

Li, W., and Godzig, A. (2006). Cd-hit: a fast program for clustering and comparing large sets of protein or nucleotide sequences. Bioinformatics 22, 1658-1659. doi: 10.1093/bioinformatics/btl158

Longstaff, D. G., Blight, S. K., Zhang, L., Green-Church, K. B., and Krzycki, J. A. (2007). In vivo contextual requirements for UAG translation as pyrrolysine. Mol. Microbiol. 63, 229-241. doi: 10.1111/j.1365-2958.2006.05500.x

Maeder, D. L., Anderson, I., Brettin, T. S., Bruce, D. C., Gilna, P., Han, C. S., et al. (2006). The Methanosarcina barkeri genome: comparative analysis with Methanosarcina acetivorans and Methanosarcina mazei reveals extensive rearrangement within methanosarcinal genomes. J. Bacteriol. 188, 7922-7931. doi: 10.1128/jb.00810-06

Mausz, M. A., and Chen, Y. (2019). Microbiology and ecology of methylated amine metabolism in marine ecosystems. Curr. Issues Mol. Biol. 33, 133-148. doi: $10.21775 / \mathrm{cimb} .033 .133$

Metcalf, W. M., Zhang, J. K., Apolinario, E., Sowers, K. R., and Wolfe, R. S. (1997). A genetic system for Archaea of the genus Methanosarcina:liposome mediated transformation and contruction of shuttle vectors. Proc. Natl. Acad. Sci. U.S.A. 94, 2626-2631. doi: 10.1073/pnas.94.6.2626

Möller, B., Ossmer, R., Howard, B. H., Gottschalk, G., and Hippe, H. (1984). Sporomusa, a new genus of Gram-negative anaerobic bacteria including Sporomusa sphaeroides spec. nov. and Sporomusa ovata spec. nov. Arch. Microbiol. 139, 388-396. doi: 10.1007/bf00408385

Muller, E., Fahlbusch, K., Walther, R., and Gottschalk, G. (1981). Formation of $\mathrm{N}, \mathrm{N}$-dimethylglycine, acetic acid, and butyric acid from betaine by Eubacterium limosum. Appl. Environ. Microbiol. 42, 439-445.

Naumann, E., Hippe, H., and Gottschalk, G. (1983). Betaine: new oxidant in the Stickland reaction and methanogenesis from betaine and L-alanine by 
a Clostridium sporogenes- Methanosarcina barkeri coculture. Appl. Environ. Microbiol. 45, 474-483.

Nielsen, M. B., Kjeldsen, K. U., and Ingvorsen, K. (2006). Desulfitibacter alkalitolerans gen. nov., sp. nov., an anaerobic, alkalitolerant, sulfite-reducing bacterium isolated from a district heating plant. Int. J. Syst. Evol. Microbiol. 56, 2831-2836. doi: 10.1099/ijs.0.64356-0

Olefeldt, D., Turetsky, M. R., Crill, P. R., and McGuire, A. D. (2013). Environmental and physical controls on northern terrestrial methane emissions across permafrost zones. Glob. Change Biol. 19, 589-603. doi: 10.1111/gcb. 12071

Picking, J. W., Behrman, E. J., Zhang, L., and Krzycki, J. A. (2019). MtpB, a member of the MttB superfamily from the human intestinal acetogen Eubacterium limosum, catalyzes proline betaine demethylation. J. Biol. Chem. 294, 1369713707. doi: 10.1074/jbc.RA119.009886

Poehlein, A., Cebulla, M., Ilg, M. M., Bengelsdorf, F. R., Schiel-Bengelsdorf, B., Whited, G., et al. (2015). Complete genome sequence of Rnf- and cytochromecontaining autotrophic acetogen clostridium aceticum DSM 1496. Genome Announc. 3:e786-15. doi: 10.1128/genomeA.00786-15

Price, M. N., Dehal, P. S., and Arkin, A. P. (2010). FastTree 2-approximately maximum-likelihood trees for large alignments. PLoS One 5:e9490. doi: 10. 1371/journal.pone.0009490

Pritchett, M. A., and Metcalf, W. W. (2005). Genetic, physiological and biochemical characterization of multiple methanol methyltransferase isozymes in Methanosarcina acetivorans C2A. Mol. Microbiol. 56, 1183-1194. doi: 10. 1111/j.1365-2958.2005.04616.x

Purdy, K. J., Nedwell, D. B., and Embley, T. M. (2003). Analysis of the sulfatereducing bacterial and methanogenic archaeal populations in contrasting antarctic sediments. Appl. Environ. Microbiol. 69, 3181-3191. doi: 10.1128/aem. 69.6.3181-3191.2003

Rebouche, C. J., and Seim, H. (1998). Carnitine metabolism and its regulation in microorganisms and mammals. Annu. Rev. Nutr. 18, 39-61. doi: 10.1146/ annurev.nutr.18.1.39

Salvi, F., Wang, Y. F., Weber, I. T., and Gadda, G. (2014). Structure of choline oxidase in complex with the reaction product glycine betaine. Acta Crystallogr. Sect. F Struct. Biol. Cryst. Commun. 70, 405-413. doi: 10.1107/ s1399004713029283

Sambrook, J., Fritsch, E. F., and Maniatis, T. (1989). Molecular Cloning: A Laboratory Manual. New York, NY: Cold Spring Harbor Laboratory.

Sattley, W. M., and Madigan, M. (2007). Cold-active acetogenic bacteria from surficial sediments of perennially ice-covered Lake Fryxell, Antarctica. FEMS Microbiol. Lett. 272, 48-54. doi: 10.1111/j.1574-6968.2007.00737.x

Sauer, K., Harms, U., and Thauer, R. K. (1997). Methanol:coenzyme M methyltransferase from Methanosarcina barkeri. Purification, properties and encoding genes of the corrinoid protein MT1. Eur. J. Biochem. 243, 670-677. doi: 10.1111/j.1432-1033.1997.t01-1-00670.x

Sauer, K., and Thauer, R. K. (1998). Methanol:coenzyme M methyltransferase from Methanosarcina barkeri-identification of the active-site histidine in the corrinoid-harboring subunit $\mathrm{MtaC}$ by site-directed mutagenesis. Eur. J. Biochem. 253, 698-705. doi: 10.1046/j.1432-1327.1998.2530698.x

Schiefner, A., Breed, J., Bosser, L., Kneip, S., Gade, J., Holtmann, G., et al. (2004). Cation-pi interactions as determinants for binding of the compatible solutes glycine betaine and proline betaine by the periplasmic ligand-binding protein prox from Escherichia coli. J. Biol. Chem. 279, 5588-5596. doi: 10.1074/jbc. m309771200

Seefeldt, L. C., and Ensign, S. A. (1994). A continuous spectrophotometric activity assay for nitrogenase using the reductant titanium (III) citrate. Anal. Biochem. 221, 379-386. doi: 10.1006/abio.1994.1429

Sharma, V., Murphy, D. P., Provan, G., and Baranov, P. V. (2012). CodonLogo: a sequence logo-based viewer for codon patterns. Bioinformatics 28, 1935-1936. doi: 10.1093/bioinformatics/bts295

Sikorski, J., Lapidus, A., Chertkov, O., Lucas, S., Copeland, A., Glavina Del Rio, T., et al. (2010). Complete genome sequence of Acetohalobium arabaticum type strain (Z-7288T). Stand. Genomic Sci. 3, 57-65. doi: 10.4056/sigs.1062906
Tallant, T. C., and Krzycki, J. A. (1997). Methylthiol:coenzyme M methyltransferase from Methanosarcina barkeri, an enzyme of methanogenesis from dimethylsulfide and methylmercaptopropionate. J. Bacteriol. 179, 6902-6911. doi: 10.1128/jb.179.22.6902-6911.1997

Tallant, T. C., Paul, L., and Krzycki, J. A. (2000). The MtsA subunit of the methylthiol:coenzyme M methyltransferase of Methanosarcina barkeri catalyses half-reactions of corrinoid dependent dimethylsulfide:coenzyme M methyl transfer. J. Biol. Chem. 276, 4485-4493. doi: 10.1074/jbc.m00751 4200

Tanaka, K. (1994). Anaerobic degradation of tetramethylammonium by a newly isolated marine methanogen. J. Ferment. Bioeng. 78, 386-388. doi: 10.1016/ 0922-338x(94)90287-9

Ticak, T., Hariraju, D., Bayron, M., Arivett, B. A., Fiester, S. E., and Ferguson, D. J. Jr. (2015). Isolation and characterization of a tetramethylammonium degrading Methanococcoides strain and a novel glycine betaine utilizing Methanolobus strain. Arch. Microbiol. 197, 197-209. doi: 10.1007/s00203-0141043-6

Ticak, T., Kountz, D., Girosky, K., Krzycki, J. A., and Ferguson, D. J. Jr. (2014). A non-pyrrolysine member of the widely distributed trimethylamine methyltransferase family is a glycine betaine methyltransferase. Proc. Natl. Acad. Sci. U.S.A. 111, E4668-E4676. doi: 10.1073/pnas.1409642111

Trott, O., and Olson, A. J. (2010). AutoDock vina: improving the speed and accuracy of docking with a new scoring function, efficient optimization, and multithreading. J. Comput. Chem. 31, 455-461. doi: 10.1002/jcc.21334

Watkins, A. J., Roussel, E. G., Parkes, R. J., and Sass, H. (2014). Glycine betaine as a direct substrate for methanogens (Methanococcoides spp.). Appl. Environ. Microbiol. 80, 289-293. doi: 10.1128/AEM.03076-13

Watkins, A. J., Roussel, E. G., Webster, G., Parkes, R. J., and Sass, H. (2012). Choline and N,N-dimethylethanolamine as direct substrates for methanogens. Appl. Environ. Microbiol. 78, 8298-8303. doi: 10.1128/AEM.01941-12

Webb, B., and Sali, A. (2017). Protein structure modeling with modeller. Meth. Mol. Biol. 1654, 39-54. doi: 10.1007/978-1-4939-7231-9_4

Webster, G., Mullins, A. J., Watkins, A. J., Cunningham-Oakes, E., Weightman, A. J., Mahenthiralingam, E., et al. (2019). Genome sequences of two choline-utilizing methanogenic archaea, Methanococcoides spp., isolated from marine sediments. Microbiol. Resour. Announc. 8:e342-19. doi: 10.1128/MRA. 00342-19

Whelan, S., and Goldman, N. (2001). A general empirical model of protein evolution derived from multiple protein families using a maximum-likelihood approach. Mol. Biol. Evol. 18, 691-699. doi: 10.1093/oxfordjournals.molbev. a003851

Wolters, J. C., Berntsson, R. P.-A., Gul, N., Karasawa, A., Thunnissen, A. M., Slotboom, D. J., et al. (2010). Ligand binding and crystal structures of the substrate-binding domain of the ABC transporter OpuA. PLoS One 5:e10361. doi: 10.1371/journal.pone.0010361

Yvon-Durocher, G., Allen, A. P., Bastviken, D., Conrad, R., Gudasz, C., St. Pierre, A., et al. (2014). Methane fluxes show consistent temperature dependence across microbial to ecosystem scales. Nature 507, 488-491. doi: 10.1038/ nature13164

Zhang, Y. (2008). I-TASSER server for protein 3D structure prediction. BMC Bioinformatics 9:40. doi: 10.1186/1471-2105-9-40

Conflict of Interest: The authors declare that the research was conducted in the absence of any commercial or financial relationships that could be construed as a potential conflict of interest.

Copyright (c) 2019 Creighbaum, Ticak, Shinde, Wang and Ferguson. This is an openaccess article distributed under the terms of the Creative Commons Attribution License (CC BY). The use, distribution or reproduction in other forums is permitted, provided the original author(s) and the copyright owner(s) are credited and that the original publication in this journal is cited, in accordance with accepted academic practice. No use, distribution or reproduction is permitted which does not comply with these terms. 